Research Paper

\title{
FUT2 genetic variants as predictors of tumor development with hepatocellular carcinoma
} \author{
Teng ${ }^{8,9 凶}$, Yung Luen $\mathrm{Yu}^{3,4,10 凶}$ \\ 1. Institute of Medicine, Chung Shan Medical University, Taichung, Taiwan; \\ 2. Department of Surgery, Taichung Veterans General Hospital, Taichung, Taiwan; \\ 3. Graduate Institute of Biomedical Sciences, China Medical University, Taichung, Taiwan; \\ 4. Center for Molecular Medicine, China Medical University Hospital, Taichung, Taiwan; \\ 5. Institute of Biotechnology, National Tsing-Hua University, Hsinchu, Taiwan; \\ 6. Division of General Surgery, Department of Surgery, Tungs' Taichung MetroHarbour Hospital, Taichung, Taiwan; \\ 7. Department of Medical Research, Chung Shan Medical University Hospital, Taichung, Taiwan; \\ 8. Department of Emergency Medicine, School of Medicine, Chung Shan Medical University, Taichung, Taiwan; \\ 9. Department of Emergency Medicine, Chung Shan Medical University Hospital, Taichung, Taiwan; \\ 10. Department of Biotechnology, Asia University, Taichung, Taiwan. \\ *These authors contributed equally to this work.
}

Chih Tien Chen ${ }^{1,2^{*}}$, Wen Ying Liao ${ }^{3,4^{*}}$, Chia Chun Hsu ${ }^{3,4,5}$, Kuan Chun Hsueh ${ }^{1,6}$, Shun Fa Yang1,7, Ying Hock

$\triangle$ Corresponding authors: Ying-Hock Teng, MD, PhD. School of Medicine, Chung Shan Medical University, Taichung, Taiwan, ROC. Fax: 886-4-24723229. E-mail: cshy392@csh.org.tw; Yung-Luen Yu, PhD. Graduate Institute of Biomedical Sciences, China Medical University, Taichung, Taiwan. E-mail: ylyu@mail.cmu.edu.tw

(C) Ivyspring International Publisher. This is an open access article distributed under the terms of the Creative Commons Attribution (CC BY-NC) license (https://creativecommons.org/licenses/by-nc/4.0/). See http://ivyspring.com/terms for full terms and conditions.

Received: 2017.02.20; Accepted: 2017.05.20; Published: 2017.07.19

\begin{abstract}
Lewis antigens related to the $A B O$ blood group are fucosylated oligosaccharides and are synthesized by specific glycosyltransferases (FUTs). FUTs are involved in various biological processes including cell adhesion and tumor progression. The fucosyltransferase-2 gene (FUT2) encodes alpha $(1,2)$ fucosyltransferase, which is responsible for the addition of the alpha $(1,2)$-linkage of fucose to glycans. Aberrant fucosylation occurs frequently during the development and progression of hepatocellular carcinoma (HCC). However, the association of FUT2 polymorphisms with HCC development has not been studied. Therefore, we aimed to investigate the association of FUT2 polymorphisms with demographic, etiological, and clinical characteristics and with susceptibility to HCC. In this study, a total of 339 patients and 720 controls were recruited. The genotypes of FUT2 at four single-nucleotide polymorphisms (SNPs; rs281377, rs 1047781 , rs601338, and rs602662) were detected by real-time polymerase chain reaction from these samples. Compared with the wild-type genotype at SNP rs 1047781, which is homozygous for nucleotides AA, at least one polymorphic T allele (AT or TT) displayed significant association with clinical stage $(p=0.048)$ and tumor size $(p=0.022)$. Our study strongly implicates the polymorphic locus rs 1047781 of FUT2 as being associated with HCC development.
\end{abstract}

Key words: Fucosyltransferase-2; Hepatocellular carcinoma; Single-nucleotide polymorphism

\section{Introduction}

Hepatocellular carcinoma (HCC) is one of the most lethal and prevalent cancers worldwide. HCC occurs frequently among Asian and African populations because of the endemic hepatitis $B$ and $C$ virus infections [1]. Recent evidence has shown that the expression of cancer-specific carbohydrate antigens (CACAs) is associated with malignant transformation [2]. Aberrant fucosylation of glycosphingolipids occurs frequently during the development and progress of HCC [3]. In a previous study, we found that several CACAs are better predictive and more sensitive biomarkers than alpha-fetoprotein (AFP) for HCC, including disialosyl galactosyl globoside (DSGG), fucosyl GM1, and Gb2 
based on an analysis with a glycan array [4]. Additionally, hepatitis B virus $X$ protein (HBX) suppresses the expression of microRNA $15 \mathrm{~b}$ (miR-15b), which directly targets fucosyltransferase 2 (FUT2) and leads to an increase in Globo $\mathrm{H}$ expression. Globo $\mathrm{H}$ is a cancer-associated carbohydrate antigen and it can synthesis by FUT2, this glycolipid highly expressed in various types of cancers, including breast cancer, liver cancer and prostate cancer cells. Overexpression of miR-15b effectively suppresses tumor growth in a mouse xenograft model of HCC [5].

FUT2 is the alpha $(1,2)$ fucosyltransferase responsible for the synthesis of Lewis type 2 (Gal $\beta 1,4-G l c N A c)$ and type 1 (Galß1,3-GlcNAc) antigen precursors and Globo $\mathrm{H}$. Increasing alpha $(1,2)$ fucosyltransferase activity changes the glycolipid composition and the cellular properties, including cell-to-cell adhesion and drug resistance, of ovarian cancer cells or tumor tissue [6]. FUT2, which is 9,980 base pairs in length, codes for the alpha $(1,2)$ fucosyltransferase [7]. Inactivating mutations in FUT2 reduce susceptibility to Helicobacter pylori infection by mediating $H$. pylori adhesion to gastric mucosa $[8,9]$. Two FUT2 mutants (739G to A, and 839T to C) are almost inactive and responsible for some non-secretor status [10].

Single-nucleotide polymorphisms (SNPs) in FUT2 have been reported that are associated with the levels of vitamin B12 [11-13]. The vitamin B12 can reduce the DNA damage and decrease the cancer incidence rate. One SNP (rs1047781) of FUT2 is the susceptible locus for recurrence of colorectal cancer in individuals from southern China [14, 15]. The association of rs1047781 with cancer antigen 19-9 (CA19-9) levels and carcinoembryonic antigen (CEA) concentration in esophageal squamous cell cancer and pancreatic cancer also was confirmed by genome-wide association studies [16]. Moreover, our previously study also shown that interactions of FUT2 polymorphisms with betel quid chewing habits maybe altering oral cancer susceptibility [17]. However, the effects of FUT2 polymorphisms are still unclear in HCC. In the present study, we aimed to investigate the association of FUT2 polymorphisms with HCC. We analyzed four SNPs (rs281377, rs1047781, rs601338, and rs602662) in exon 2 region of FUT2 gene for associations with demographic, etiological, and clinical characteristics and with susceptibility to HCC.

\section{Materials and Methods}

\section{Study subjects and specimen collection}

This hospital-based case-control study recruited 339 patients with HCC between 2010 and
2015 from the Chung Shan Medical University Hospital in Taichung, Taiwan, to serve as the case group. The diagnosis of HCC was made according to the criteria specified in the national guidelines for HCC. HCC patients were clinically staged at the time of diagnosis according to the tumor/node/metastasis staging system of the American Joint Committee on Cancer (2002). For control group, all 720 control individuals were recruited at the same hospital and these control individuals had neither self-reported history of cancer of any sites. The patients' clinic pathological characteristics, including clinical staging, lymph node metastasis, and histopathologic grading levels, were verified by chart review. Whole-blood specimens collected from the controls and HCC patients were placed in tubes containing EDTA, immediately centrifuged, and stored at $-80^{\circ} \mathrm{C}$. Study protocols were approved by the institutional review of the Taichung Chung Shan Medical University Hospital. All methods were carried out in accordance with the approved guidelines. All subjects provided written informed consent before participating in the study.

\section{Selection of FUT2 polymorphisms}

Four SNPs in FUT2 (NM_000511) were selected from the International HapMap Project data for this study. We included the synonymous SNP rs281377 and non-synonymous SNPs rs1047781, rs601338, and rs602662, all of which are located in the exon region of FUT2 gene.

\section{FUT2 Genotyping}

Allelic discrimination of the FUT2 polymorphisms rs281377, rs1047781, rs601338, and rs602662 was assessed using an ABI StepOne Real-Time PCR System (Applied Biosystems), SDS v3.0 software (Applied Biosystems), and the TaqMan assay [17-19]. The final volume for each reaction was 5 $\mu \mathrm{L}$, containing $2.5 \mu \mathrm{L}$ TaqMan Genotyping Master Mix, $0.125 \mu \mathrm{L}$ TaqMan probes mix, and $10 \mathrm{ng}$ genomic DNA. The reaction conditions included an initial denaturation step at $95^{\circ} \mathrm{C}$ for $10 \mathrm{~min}$ followed by 40 cycles at $95^{\circ} \mathrm{C}$ for $15 \mathrm{sec}$ and $60^{\circ} \mathrm{C}$ for $1 \mathrm{~min}$.

\section{Statistical analysis}

A Mann-Whitney U-test was used to compare differences in age and demographic characteristics between controls groups and HCC patients. The odds ratios (ORs) with 95\% confidence intervals (CIs) were estimated by logistic regression models. The adjusted odds ratios (AORs) with 95\% CIs of the association between genotype frequencies and HCC risk as well as clinical pathological characteristics were estimated by multiple logistic regression models after controlling for other covariates. Values of $p<0.05$ 
were considered significant. The data were analyzed using SAS statistical software (Version 9.1, 2005; SAS Institute Inc., Cary, NC).

Table 1. Demographic characteristics and clinical parameters for 720 controls and 339 patients with HCC.

\begin{tabular}{|c|c|c|c|}
\hline Variable & $\begin{array}{l}\text { Controls }(\mathrm{N}= \\
720)\end{array}$ & $\begin{array}{l}\text { HCC patients (N } \\
=339)\end{array}$ & $p$-value \\
\hline Age (yr) & $\begin{array}{l}\text { Mean } \pm \text { S.D. } \\
52.26 \pm 10.08\end{array}$ & $\begin{array}{l}\text { Mean } \pm \text { S.D. } \\
62.99 \pm 11.65\end{array}$ & $<0.001^{*}$ \\
\hline Gender & n (\%) & n (\%) & \\
\hline Male & $590(81.9 \%)$ & $242(71.4 \%)$ & \\
\hline Female & $130(18.1 \%)$ & $97(28.6 \%)$ & $<0.001^{*}$ \\
\hline \multicolumn{4}{|c|}{ Alcohol consumption } \\
\hline No & $598(83.1 \%)$ & $214(63.1 \%)$ & \\
\hline Yes & $122(16.9 \%)$ & $125(36.9 \%)$ & $<0.001^{*}$ \\
\hline \multicolumn{4}{|c|}{ Tobacco consumption } \\
\hline No & $413(57.4 \%)$ & $202(59.6 \%)$ & \\
\hline Yes & 307 (42.6\%) & $137(40.4 \%)$ & 0.493 \\
\hline \multicolumn{4}{|c|}{ HCC stage } \\
\hline I or II & & $222(65.5 \%)$ & \\
\hline III or IV & & $117(34.5 \%)$ & \\
\hline \multicolumn{4}{|c|}{ Tumor T status } \\
\hline$\leq \mathrm{T} 2$ & & $225(66.4 \%)$ & \\
\hline$>\mathrm{T} 2$ & & $114(33.6 \%)$ & \\
\hline \multicolumn{4}{|c|}{ Lymph node status } \\
\hline No & & 328 (96.8\%) & \\
\hline $\mathrm{N} 1+\mathrm{N} 2$ & & $11(3.2 \%)$ & \\
\hline \multicolumn{4}{|c|}{ Metastasis } \\
\hline M0 & & $321(94.7 \%)$ & \\
\hline M1 & & $18(5.3 \%)$ & \\
\hline \multicolumn{4}{|c|}{ Vascular invasion } \\
\hline No & & $278(82.0 \%)$ & \\
\hline Yes & & $61(18.0 \%)$ & \\
\hline
\end{tabular}

\section{Results}

For this case-cohort study, 720 healthy controls and 339 patients with HCC were recruited. According to our analysis of the demographic characteristics and the etiological and clinical characteristics of HCC among these individuals (Table 1), we found that age $(p<0.001)$, gender $(p<0.001)$, and alcohol consumption $(p<0.001)$ were significantly associated with HCC risk. HCC was more common in individuals over 60 years old, in males, and in those who have a history of alcohol consumption. To decrease the possible interference of several environmental factors, the AORs and their 95\% CIs were estimated after controlling for the risk related to age, gender, alcohol consumption, and tobacco use in each comparison by multiple logistic regression models. The distribution frequency of FUT2 genotypes in both controls and HCC patients is shown in Table 2. Alleles with the highest distribution frequency were as follows: homozygous $\mathrm{T} / \mathrm{T}$ for rs281377, heterozygous A/T for rs1047781, and homozygous G/G for both rs601338 and rs602662. There was no significant difference with respect to rs281377, rs1047781, rs601338, and rs602662 polymorphisms of FUT2 between healthy controls and patients with HCC.

Table 2. Distribution frequency of FUT2 genotypes in 720 controls and 339 patients with HCC.

\begin{tabular}{|c|c|c|c|c|}
\hline Variable & $\begin{array}{l}\text { Controls }(\mathrm{N} \\
=720) \mathrm{n}(\%)\end{array}$ & $\begin{array}{l}\text { Patients (N } \\
=339) \text { n (\%) }\end{array}$ & OR (95\% CI) & AOR $(95 \% \mathrm{CI})$ \\
\hline \multicolumn{5}{|l|}{ rs281377 } \\
\hline TT & $534(74.2 \%)$ & 259 (76.4\%) & 1.00 & 1.00 \\
\hline TC & $174(24.2 \%)$ & $75(22.1 \%)$ & $\begin{array}{l}0.889 \\
(0.653-1.210)\end{array}$ & $\begin{array}{l}1.069 \\
(0.722-1.582)\end{array}$ \\
\hline CC & $12(1.6 \%)$ & $5(1.5 \%)$ & $\begin{array}{l}0.859 \\
(0.299-2.464)\end{array}$ & $\begin{array}{l}0.502 \\
(0.123-2.047)\end{array}$ \\
\hline $\mathrm{TC}+\mathrm{CC}$ & $186(25.8 \%)$ & $80(23.6 \%)$ & $\begin{array}{l}0.887 \\
(0.656-1.198)\end{array}$ & $\begin{array}{l}1.018 \\
(0.693-1.494)\end{array}$ \\
\hline
\end{tabular}

$\begin{array}{lllll}\text { rs1047781 } & & & & \\ \text { AA } & 217(30.2 \%) & 95(28.0 \%) & 1.00 & 1.00 \\ \text { AT } & 363(50.4 \%) & 169(49.9 \%) & 1.063 & 1.020 \\ & & & (0.786-1.439) & (0.697-1.493) \\ \text { TT } & 140(19.4 \%) & 75(22.1 \%) & 1.224 & 1.106 \\ & & & (0.845-1.771) & (0.690-1.771) \\ \text { AT + TT } & 503(69.8 \%) & 244(72.0 \%) & 1.108 & 1.044 \\ & & & (0.833-1.474) & (0.730-1.495)\end{array}$

rs601338

GG $\quad 715(99.3 \%) \quad 336(99.1 \%) \quad 1.00 \quad 1.00$

GA $\quad 5(0.7 \%) \quad 3(0.9 \%) \quad 1.277 \quad 0.694$

$(0.303-5.374) \quad(0.076-6.361)$

$\begin{array}{lllll}\mathrm{AA} & 0(0 \%) & 0(0 \%) & - & -\end{array}$

$\mathrm{GA}+\mathrm{AA} \quad 5(0.7 \%) \quad 3(0.9 \%) \quad 1.277 \quad 0.694$

$(0.303-5.374) \quad(0.076-6.361)$

$\begin{array}{lllll}\text { rs602662 } & & & & \\ \text { GG } & 715(99.3 \%) & 336(99.1 \%) & 1.00 & 1.00 \\ \text { GA } & 5(0.7 \%) & 3(0.9 \%) & 1.277 & 0.694 \\ & & & (0.303-5.374) & (0.076-6.361) \\ \text { AA } & 0(0 \%) & 0(0 \%) & - & - \\ \text { GA + AA } & 5(0.7 \%) & 3(0.9 \%) & 1.277 & 0.694 \\ & & & (0.303-5.374) & (0.076-6.361)\end{array}$

The odds ratios (ORs) and their $95 \%$ confidence intervals (CIs) were estimated by logistic regression models. The adjusted odds ratios (AORs) and their 95\% CIs were estimated by multiple logistic regression models after controlling for age, gender, alcohol consumption, and tobacco use.

We further investigated the effects of polymorphic genotypes of FUT2 (rs281377 and rs1047781) on the clinical status of HCC (Table 3 and Table 4). Based on the genotypic frequencies of rs281377 and rs1047781, only FUT2 rs1047781 showed a significant association with clinical stage $(p=0.048)$, tumor size $(p=0.022)$, and the absence of anti-HCV antibodies $(p=0.037)$. In the routine blood tests carried out in conjunction with a HCC diagnosis, including alpha-fetoprotein (AFP), alanine aminotransferase (ALT), and aspartate aminotransferase (AST), we demonstrated that at least one polymorphic $\mathrm{T}$ allele of rs1047781 displayed a high association with the ratio of AST/ALT ( $p=0.037)$ as compared with the wild-type genotype (Table 5). 
Table 3. Odds ratio (OR) and $95 \%$ confidence interval $(\mathrm{Cl})$ of clinical status and FUT2 rs281377 genotypic frequencies in 339 HCC patients.

\begin{tabular}{|c|c|c|c|c|}
\hline \multirow[t]{2}{*}{ Variable } & \multicolumn{2}{|c|}{ Genotypic frequencies } & \multirow[b]{2}{*}{ OR $(95 \% \mathrm{CI})$} & \multirow[b]{2}{*}{$p$-value } \\
\hline & $\begin{array}{l}\text { TT }(N= \\
259)\end{array}$ & $\begin{array}{l}\mathrm{TC}+\mathrm{CC}(\mathrm{N}= \\
80)\end{array}$ & & \\
\hline \multicolumn{5}{|c|}{ HCC Stage } \\
\hline I or II & $171(66.0 \%)$ & $51(63.8 \%)$ & 1.00 & 0.709 \\
\hline III or IV & $88(34.0 \%)$ & $29(36.2 \%)$ & $\begin{array}{l}1.105 \\
(0.655-1.865)\end{array}$ & \\
\hline \multicolumn{5}{|c|}{ Tumor size } \\
\hline$\leq \mathrm{T} 2$ & $174(67.2 \%)$ & $51(63.8 \%)$ & 1.00 & 0.570 \\
\hline$>\mathrm{T} 2$ & $85(32.8 \%)$ & $29(36.2 \%)$ & $\begin{array}{l}1.164 \\
(0.689-1.967)\end{array}$ & \\
\hline \multicolumn{5}{|c|}{$\begin{array}{l}\text { Lymph node } \\
\text { metastasis }\end{array}$} \\
\hline No & $253(97.7 \%)$ & $75(93.8 \%)$ & 1.00 & 0.083 \\
\hline Yes & $6(2.3 \%)$ & $5(6.2 \%)$ & $\begin{array}{l}2.811 \\
(0.835-9.469)\end{array}$ & \\
\hline \multicolumn{5}{|c|}{ Distant metastasis } \\
\hline No & $246(95.0 \%)$ & $75(93.8 \%)$ & 1.00 & 0.668 \\
\hline Yes & $13(5.0 \%)$ & $5(6.2 \%)$ & $\begin{array}{l}1.262 \\
(0.436-3.653)\end{array}$ & \\
\hline \multicolumn{5}{|c|}{ Vascular invasion } \\
\hline No & $215(83.0 \%)$ & $63(78.8 \%)$ & 1.00 & 0.386 \\
\hline Yes & $44(17.0 \%)$ & $17(21.2 \%)$ & $\begin{array}{l}1.319 \\
(0.705-2.466)\end{array}$ & \\
\hline \multicolumn{5}{|c|}{ Child-Pugh grade } \\
\hline A & $197(76.1 \%)$ & $61(76.3 \%)$ & 1.00 & 0.972 \\
\hline B or C & $62(23.9 \%)$ & $19(23.7 \%)$ & $\begin{array}{l}0.990 \\
(0.549-1.783)\end{array}$ & \\
\hline \multicolumn{5}{|l|}{ HBsAg } \\
\hline Negative & $151(58.3 \%)$ & $47(58.8 \%)$ & 1.00 & 0.943 \\
\hline Positive & $108(41.7 \%)$ & $33(41.2 \%)$ & $\begin{array}{l}0.982 \\
(0.590-1.633)\end{array}$ & \\
\hline \multicolumn{5}{|l|}{ Anti-HCV } \\
\hline Negative & $140(54.1 \%)$ & $37(46.3 \%)$ & 1.00 & 0.222 \\
\hline Positive & $119(45.9 \%)$ & $43(53.7 \%)$ & $\begin{array}{l}1.367 \\
(0.827-2.216)\end{array}$ & \\
\hline \multicolumn{5}{|c|}{ Liver cirrhosis } \\
\hline Negative & $56(21.6 \%)$ & $11(13.8 \%)$ & 1.00 & 0.122 \\
\hline Positive & $203(78.4 \%)$ & $69(86.2 \%)$ & $\begin{array}{l}1.730 \\
(0.858-3.491)\end{array}$ & \\
\hline
\end{tabular}

The ORs and their 95\% CIs were estimated based on logistic regression models $>$ T2: multiple tumors of $>5 \mathrm{~cm}$ in diameter or tumor(s) involving a major branch of the portal vein or hepatic veins.

\section{Discussion}

FUT2 encodes alpha $(1,2)$ fucosyltransferase, which catalyzes the addition of terminal alpha $(1,2)$ fucose residues on glycans such as Globo $\mathrm{H}$ and Lewis $\mathrm{Y}$. Increasing evidence indicates that Globo $\mathrm{H}$ and Lewis $\mathrm{Y}$ are highly overexpressed in various types of malignant tumors including breast, liver, prostate, and pancreatic cancer [3, 20-23]. Although it is generally accepted that FUT2 has an important role in cancer, associations between FUT2 polymorphisms and clinical characteristics of HCC have not been analyzed. Thus, we assessed whether FUT2 SNPs are associated with HCC risk or with the clinical features of HCC.

FUT2 is associated with several chronic diseases such as Crohn's disease and several autoimmune or immune-mediated chronic diseases [24, 25]. For example, FUT1/FUT2 is predominantly expressed in M1 inflammatory macrophages, and the expression of these genes is highly correlated with the level of TNF (which encodes tumor necrosis factor) in patients with rheumatoid arthritis (RA) [26]. In addition, the non-secretor allele of FUT2 SNP rs601338 confers susceptibility to type 1 diabetes and resistance to infections [25]. About $90 \%$ of HCC cases arise in individuals with chronic liver inflammation and fibrosis caused by damage to the liver by, for example, alcohol consumption [27, 28]. Indeed, in our current data, we observed that alcohol consumption was associated with HCC (Table 1) and that the non-secretor allele of FUT2 SNP rs1047781 displayed significant association with the AST/ALT ratio, which is an indicator of liver damage (Table 5). Based on a test for alkaline phosphatase (ALP) in the blood, it has recently been reported that preoperative ALP levels could be used to monitor and predict recurrence in high-risk HCC patients [29]. The FUT1 SNP rs2071699 and the FUT2 SNP rs1047781 are also associated with serum ALP levels among the Japanese population [30].

FUT2 includes some ethnic group-specific polymorphisms [31], but the non-secretor phenotypes are present within most populations [32]. In the present study, we included the synonymous SNP rs281377 and non-synonymous SNPs rs1047781, rs601338, and rs602662 as candidate SNPs to investigate the association with HCC development. The wild-type rs1047781 (A) encodes the "secretor" allele of FUT2, whereas rs1047781 (T) encodes the non-secretor allele. The presence of at least one polymorphic $\mathrm{T}$ allele of rs1047781 resulted in a high association with a clinical stage of III or IV and with larger tumor size for individuals with HCC (Table 4). In addition, FUT2 rs1047781 may be the susceptible locus for recurrence of colorectal cancer in a population from southern China [14]. Overexpression of Lewis Y, which is the glycan product of FUT1 and FUT2, promotes human epididymis protein 4-mediated invasion and metastasis of ovarian cancer [33]. HCC is a highly vascularized tumor with frequent intrahepatic metastasis [34-36]. Cheng et al. noted that Globo $\mathrm{H}$, which is another glycan product of FUT2, might shed from cancer cells through microvesicles, resulting in enhanced angiogenic activity [37].

We found no significant association between FUT2 polymorphisms and AFP levels, which is similar to findings from a previous study of individuals with HCC [16]. Recently, the use of AFP levels in HCC diagnosis has been doubted because of the significant rates of false-positive and 
false-negative findings [38]. By using a glycan array, we recently identified several CACAs that have a better predictive sensitivity than AFP [4]. In addition, alpha-fetoprotein fraction L3 (AFP-L3), which is synthesized by malignant cells and incorporates a fucosylated oligosaccharide, has been shown to be a better early diagnostic and prognostic marker for $\operatorname{HCC}[39,40]$.

In conclusion, our findings suggest that gene-clinical characteristic interactions might alter the susceptibility for HCC development. This study provides new information on the association of FUT2 polymorphisms with the clinical pathology of HCC in the Taiwanese population.

Table 4. Odds ratio (OR) and $95 \%$ confidence interval $(\mathrm{Cl})$ of clinical status and FUT2 rs 1047781 genotypic frequencies in 339 HCC patients.

\begin{tabular}{|c|c|c|c|c|}
\hline \multirow[t]{2}{*}{ Variable } & \multicolumn{2}{|c|}{ Genotypic frequencies } & \multirow[b]{2}{*}{ OR $(95 \% \mathrm{CI})$} & \multirow[b]{2}{*}{$p$-value } \\
\hline & $\begin{array}{l}\text { AA (N = } \\
95)\end{array}$ & $\begin{array}{l}\mathrm{AT}+\mathrm{TT}(\mathrm{N}= \\
244)\end{array}$ & & \\
\hline \multicolumn{5}{|c|}{ HCC stage } \\
\hline I or II & $70(73.7 \%)$ & $152(62.3 \%)$ & 1.00 & $0.048^{*}$ \\
\hline III or IV & $25(26.3 \%)$ & $92(37.7 \%)$ & $\begin{array}{l}1.695 \\
(1.003-2.865)\end{array}$ & \\
\hline \multicolumn{5}{|c|}{ Tumor size } \\
\hline$\leq \mathrm{T} 2$ & $72(75.8 \%)$ & $153(62.7 \%)$ & 1.00 & $0.022^{*}$ \\
\hline$>\mathrm{T} 2$ & $23(24.2 \%)$ & $91(37.3 \%)$ & $\begin{array}{l}1.862 \\
(1.089-3.183)\end{array}$ & \\
\hline \multicolumn{5}{|c|}{$\begin{array}{l}\text { Lymph node } \\
\text { metastasis }\end{array}$} \\
\hline No & $91(95.8 \%)$ & $237(97.1 \%)$ & 1.00 & 0.531 \\
\hline Yes & $4(4.2 \%)$ & $7(2.9 \%)$ & $\begin{array}{l}0.672 \\
(0.192-2.350)\end{array}$ & \\
\hline \multicolumn{5}{|c|}{ Distant metastasis } \\
\hline No & $89(93.7 \%)$ & $232(95.1 \%)$ & 1.00 & 0.606 \\
\hline Yes & $6(6.3 \%)$ & $12(4.9 \%)$ & $\begin{array}{l}0.767 \\
(0.279-2.107)\end{array}$ & \\
\hline \multicolumn{5}{|c|}{ Vascular invasion } \\
\hline No & $82(86.3 \%)$ & $196(80.3 \%)$ & 1.00 & 0.197 \\
\hline Yes & $13(13.7 \%)$ & $48(19.7 \%)$ & $\begin{array}{l}1.545 \\
(0.795-3.003)\end{array}$ & \\
\hline \multicolumn{5}{|c|}{ Child-Pugh grade } \\
\hline $\mathrm{A}$ & $75(78.9 \%)$ & $183(75.0 \%)$ & 1.00 & 0.444 \\
\hline $\mathrm{B}$ or $\mathrm{C}$ & $20(21.1 \%)$ & $61(25.0 \%)$ & $\begin{array}{l}1.250 \\
(0.705-2.215)\end{array}$ & \\
\hline \multicolumn{5}{|l|}{ HBsAg } \\
\hline Negative & $58(61.1 \%)$ & $140(57.4 \%)$ & 1.00 & 0.537 \\
\hline Positive & $37(38.9 \%)$ & $104(42.6 \%)$ & $\begin{array}{l}1.164 \\
(0.718-1.890)\end{array}$ & \\
\hline \multicolumn{5}{|c|}{ Anti-HCV } \\
\hline Negative & $41(43.2 \%)$ & $136(55.7 \%)$ & 1.00 & $0.037^{*}$ \\
\hline Positive & $54(56.8 \%)$ & $108(44.3 \%)$ & $\begin{array}{l}0.603 \\
(0.374-0.973)\end{array}$ & \\
\hline \multicolumn{5}{|c|}{ Liver cirrhosis } \\
\hline Negative & $20(21.1 \%)$ & $47(19.3 \%)$ & 1.00 & 0.710 \\
\hline Positive & $75(78.9 \%)$ & $197(80.7 \%)$ & $\begin{array}{l}1.118 \\
(0.621-2.010)\end{array}$ & \\
\hline
\end{tabular}

The ORs and their $95 \%$ CIs were estimated by logistic regression models. $>$ T2 multiple tumors of $>5 \mathrm{~cm}$ in diameter or tumor(s) involving a major branch of the portal vein or hepatic veins. ${ }^{*} p<0.05$.
Table 5. Association of FUT2 genotypic frequencies with HCC-related laboratory status.

\begin{tabular}{lllll}
\hline Characteristic & $\begin{array}{l}\text { a-Fetoprotein } \\
\text { (ng/mL) }\end{array}$ & $\begin{array}{l}\text { ASTa } \\
\text { (IU/L) }\end{array}$ & $\begin{array}{l}\text { ALTa } \\
\text { (IU/L) }\end{array}$ & $\begin{array}{l}\text { AST/ALT } \\
\text { ratio }^{\text {a }}\end{array}$ \\
\hline rs281377 & & & & \\
TT & $3381.7 \pm 966.6$ & $129.3 \pm 16.6$ & $108.0 \pm 12.7$ & $1.53 \pm 0.10$ \\
TC + CC & $3979.4 \pm 2150.3$ & $154.4 \pm 39.3$ & $133.6 \pm 31.6$ & $1.35 \pm 0.09$ \\
$p$ value & 0.777 & 0.498 & 0.376 & 0.331
\end{tabular}

rs1047781

$\begin{array}{lllll}\text { AA } & 3927.2 \pm 1899.4 & 108.5 \pm 21.5 & 108.0 \pm 25.0 & 1.22 \pm 0.07\end{array}$

$\begin{array}{lllll}\mathrm{AT}+\mathrm{TT} & 3365.3 \pm 1001.2 & 145.6 \pm 20.1 & 116.3 \pm 14.0 & 1.59 \pm 0.11\end{array}$

$\begin{array}{lllll}p \text { value } & 0.778 & 0.288 & 0.761 & 0.037^{*}\end{array}$

Mann-Whitney U-test was used between two groups.

aMean \pm S.E.

\section{Acknowledgements}

This study was supported by grants from the Ministry of Science and Technology, Taiwan (MOST103-2320-B-039-052-MY3; MOST105-2321-B039-002) and the Ministry of Health and Welfare (MOHW106-TDU-B-212-144-003).

\section{Competing Interests}

The authors have no conflict of interest.

\section{References}

[1] Huy TT, Abe K. Molecular epidemiology of hepatitis B and C virus infections in Asia. Pediatr Int 2004; 46: 223-230.

[2] Fuster MM, Esko JD. The sweet and sour of cancer: glycans as novel therapeutic targets. Nat Rev Cancer 2005; 5: 526-542.

[3] Zhu J, Wang Y, Yu Y, et al. Aberrant fucosylation of glycosphingolipids in human hepatocellular carcinoma tissues. Liver Int 2014; 34: 147-160.

[4] Wu CS, Yen CJ, Chou RH, et al. Cancer-associated carbohydrate antigens as potential biomarkers for hepatocellular carcinoma. PLoS One 2012; 7: e39466.

[5] Wu CS, Yen CJ, Chou RH, et al. Downregulation of microRNA-15b by hepatitis $\mathrm{B}$ virus $\mathrm{X}$ enhances hepatocellular carcinoma proliferation via fucosyltransferase 2-induced Globo H expression. Int J Cancer 2014; 134: 1638-1647.

[6] Iwamori M, Tanaka K, Kubushiro K, et al. Alterations in the glycolipid composition and cellular properties of ovarian carcinoma-derived RMG-1 cells on transfection of the alpha1,2-fucosyltransferase gene. Cancer Sci 2005; 96: 26-30.

[7] Liu Y, Fujitani N, Koda Y, Soejima M, Kimura H. Presence of H type 3/4 chains of $\mathrm{ABO}$ histo-blood group system in serous cells of human submandibular gland and regulation of their expression by the secretor gene (FUT2). J Histochem Cytochem 1999; 47: 889-894.

[8] Ikehara $Y$, Nishihara S, Yasutomi $\mathrm{H}$, et al. Polymorphisms of two fucosyltransferase genes (Lewis and Secretor genes) involving type I Lewis antigens are associated with the presence of anti-Helicobacter pylori IgG antibody. Cancer Epidemiol Biomarkers Prev 2001; 10: 971-977.

[9] Magalhaes A, Gomes J, Ismail MN, et al. Fut2-null mice display an altered glycosylation profile and impaired BabA-mediated Helicobacter pylori adhesion to gastric mucosa. Glycobiology 2009; 19: 1525-1536.

[10] Serpa J, Mendes N, Reis CA, et al. Two new FUT2 (fucosyltransferase 2 gene) missense polymorphisms, 739G-->A and 839T-->C are partly responsible for non-secretor status in a Caucasian population from Northern Portugal. Biochem J 2004; 383: 469-474.

[11] Hazra A, Kraft P, Selhub J, et al. Common variants of FUT2 are associated with plasma vitamin B12 levels. Nat Genet 2008; 40: 1160-1162.

[12] Lin X, Lu D, Gao Y, et al. Genome-wide association study identifies novel loci associated with serum level of vitamin B12 in Chinese men. Hum Mol Genet 2012; 21: 2610-2617.

[13] Tanwar VS, Chand MP, Kumar J, et al. Common variant in FUT2 gene is associated with levels of vitamin B(12) in Indian population. Gene 2013; 515: 224-228.

[14] Liang Y, Tang W, Huang T, et al. Genetic variations affecting serum carcinoembryonic antigen levels and status of regional lymph nodes in patients with sporadic colorectal cancer from Southern China. PLoS One 2014; 9: e97923. 
[15] Hu D, Zhang D, Zheng S, Guo M, Lin X, Jiang Y. Association of Ulcerative Colitis with FUT2 and FUT3 Polymorphisms in Patients from Southeast China. PLoS One 2016; 11: e0146557.

[16] $\mathrm{He} \mathrm{M}, \mathrm{Wu} \mathrm{C}, \mathrm{Xu} \mathrm{J}$, et al. A genome wide association study of genetic loci that influence tumour biomarkers cancer antigen 19-9, carcinoembryonic antigen and alpha fetoprotein and their associations with cancer risk. Gut 2014; 63: 143-151.

[17] Su KJ, Ho CC, Lin CW, et al. Combinations of FUT2 gene polymorphisms and environmental factors are associated with oral cancer risk. Tumour Biol 2016; 37: 6647-6652.

[18] Huang WS, Lin HY, Yeh CB, et al. Correlation of Chitinase 3-Like 1 Single Nucleotide Polymorphisms with Hepatocellular Carcinoma in Taiwan. Int J Med Sci 2017; 14: 136-142.

[19] Cheng HL, Liu YF, Su CW, et al. Functional genetic variant in the Kozak sequence of WW domain-containing oxidoreductase (WWOX) gene is associated with oral cancer risk. Oncotarget 2016; 7: 69384-69396.

[20] Hellstrom I, Garrigues HJ, Garrigues U, Hellstrom KE. Highly tumor-reactive, internalizing, mouse monoclonal antibodies to Le(y)-related cell surface antigens. Cancer Res 1990; 50: 2183-2190.

[21] Scott AM, Geleick D, Rubira M, et al. Construction, production, and characterization of humanized anti-Lewis Y monoclonal antibody 3 S193 for targeted immunotherapy of solid tumors. Cancer Res 2000; 60: 3254-3261.

[22] Le Pendu J, Marionneau S, Cailleau-Thomas A, et al. ABH and Lewis histo-blood group antigens in cancer. APMIS 2001; 109: 9-31.

[23] Chang WW, Lee CH, Lee P, et al. Expression of Globo $\mathrm{H}$ and SSEA3 in breast cancer stem cells and the involvement of fucosyl transferases 1 and 2 in Globo H synthesis. Proc Natl Acad Sci U S A 2008; 105: 11667-11672.

[24] Hu DY, Shao XX, Xu CL, et al. Associations of FUT2 and FUT3 gene polymorphisms with Crohn's disease in Chinese patients. J Gastroenterol Hepatol 2014; 29: 1778-1785.

[25] Smyth DJ, Cooper JD, Howson JM, et al. FUT2 nonsecretor status links type 1 diabetes susceptibility and resistance to infection. Diabetes 2011; 60:3081-3084.

[26] Li J, Hsu HC, Ding Y, et al. Inhibition of fucosylation reshapes inflammatory macrophages and suppresses type II collagen-induced arthritis. Arthritis Rheumatol 2014; 66: 2368-2379.

[27] Weber A, Boege Y, Reisinger F, Heikenwalder M. Chronic liver inflammation and hepatocellular carcinoma: persistence matters. Swiss Med Wkly 2011; 141: w13197.

[28] Bishayee A. The role of inflammation and liver cancer. Adv Exp Med Biol 2014; 816: 401-435.

[29] Yu MC, Chan KM, Lee CF, et al. Alkaline phosphatase: does it have a role in predicting hepatocellular carcinoma recurrence? J Gastrointest Surg 2011; 15: 1440-1449.

[30] Masuda M, Okuda K, Ikeda DD, Hishigaki H, Fujiwara T. Interaction of genetic markers associated with serum alkaline phosphatase levels in the Japanese population. Hum Genome Var 2015; 2: 15019.

[31] Koda Y, Tachida H, Pang H, et al. Contrasting patterns of polymorphisms at the ABO-secretor gene (FUT2) and plasma alpha(1,3)fucosyltransferase gene (FUT6) in human populations. Genetics 2001; 158: 747-756.

[32] Soejima M, Pang H, Koda Y. Genetic variation of FUT2 in a Ghanaian population: identification of four novel mutations and inference of balancing selection. Ann Hematol 2007; 86: 199-204.

[33] Zhuang H, Hu Z, Tan M, et al. Overexpression of Lewis y antigen promotes human epididymis protein 4-mediated invasion and metastasis of ovarian cancer cells. Biochimie 2014; 105: 91-98.

[34] Muto J, Shirabe K, Sugimachi K, Maehara Y. Review of angiogenesis in hepatocellular carcinoma. Hepatol Res 2015; 45: 1-9.

[35] Wang R, Zhao N, Li S, et al. MicroRNA-195 suppresses angiogenesis and metastasis of hepatocellular carcinoma by inhibiting the expression of VEGF, VAV2, and CDC42. Hepatology 2013; 58: 642-653.

[36] Fang JH, Zhou HC, Zeng C, et al. MicroRNA-29b suppresses tumor angiogenesis, invasion, and metastasis by regulating matrix metalloproteinase 2 expression. Hepatology 2011; 54: 1729-1740.

[37] Cheng JY, Wang SH, Lin J, et al. Globo-H ceramide shed from cancer cells triggers translin-associated factor X-dependent angiogenesis. Cancer Res 2014; 74: 6856-6866

[38] Kim H, Kim K, Jin J, et al. Measurement of glycosylated alpha-fetoprotein improves diagnostic power over the native form in hepatocellular carcinoma. PLoS One 2014; 9: e110366.

[39] Cheng J, Wang W, Zhang Y, et al. Prognostic role of pre-treatment serum AFP-L3\% in hepatocellular carcinoma: systematic review and meta-analysis. PLoS One 2014; 9: e87011.

[40] Wu CS, Lee TY, Chou RH, et al. Development of a highly sensitive glycan microarray for quantifying AFP-L3 for early prediction of hepatitis B virus-related hepatocellular carcinoma. PLoS One 2014; 9: e99959. 